\section{MITI reshuffles institutes to keep up with the times}

Tokyo. The Agency of Industrial Science and Technology (AIST), the main research component of Japan's Ministry of International Trade and Industry (MITI), last month implemented the first major reorganization in decades of four of its nine research institutes in Tsukuba science city, northeast of Tokyo.

The four institutes - the National Chemical Laboratory for Industry, the Fermentation Research Institute, the Research Institute for Polymers and Science and the Industrial Products Research Institute have been combined into three: one for materials science, another for bioscience and the third a new style of interdisciplinary research institute intended to increase the flexibility of the ministry's research system. The interdisciplinary research institute will play an important role in a new $¥ 25$ billion (US $\$ 215$ million) government-industry project to develop nanotechnology (see below).

The four institutes were created before the Second World War and were moved to Tsukuba in the 1970s. Their original research goals, as described by their names, are no longer relevant to trends in science and technology, leading some researchers in Tsukuba to refer to them as 'dinosaurs'

In addition to restructuring completely the institutes' research departments, MITI has re-written Japan's laws to make it easier for the institutes to employ outside researchers from universities, companies and overseas on temporary contracts or for cooperative research. More than a third of the 1,100 or so researchers at the new institutes come from outside the institutes (see table).

The National Institute for Advanced Interdisciplinary Research is expected to employ a flexible management system rather than the traditional rigid structure of national laboratories. The institute will carry out research on the basis of individual projects, and the projects will be reviewed every 3-5 years by outsiders, including foreign scientists.

The extended review process is controversial, but the agency is determined to introduce it and hopes to extend it to other AIST institutes. If successful, the institute will be the first national institute to follow in the footsteps of Tokyo University, which recently carried out an external review of its physics department by a panel of distinguished foreign and Japanese scientists (see Nature 360, 403; 1992).

In its first year of operation, the interdisciplinary institute will concentrate on nanotechnology, cluster science and bionic design. That focus is expected to be broadened in the future.

The researchers in the three new institutes are now "spread like a mosaic" through the four buildings of the four former institutes, says Osamu Moriya, deputy director of AIST's general coordination division. Starting next year, members of the National Institute of Bioscience and Human Technology will be housed in the former Fermentation Research Institute as well as in a nearby building under construction.

Researchers at the National Institute of Material and Chemical Research will occupy the former National Chemical Laboratory and the adjacent building of the former Research Institute for Polymers and Textiles, which will have a new wing connected by a passageway to the chemical laboratory building. And scientists at the interdisciplinary institute will use the former Industrial Products Research Institute. More than a hundred researchers will be affected by the moves, and construction will cost several billion yen.

Moriya says that the interdisciplinary institute will eventually double its size, to 70-100 permanent staff. Nearly $¥ 1,400$ million (US\$12 million) has already been spent on new
University company and foreign researchers

Permanent staff

National Institute for Advanced Interdisciplinary Research

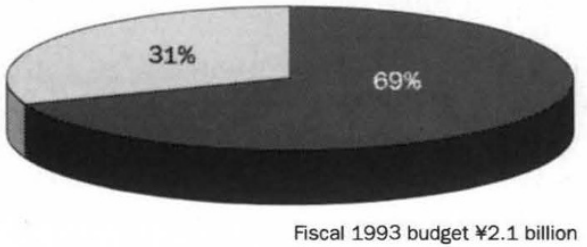

National Institute of Material and Chemical Research

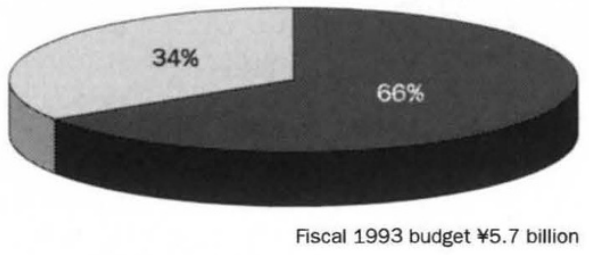

National Institute of Bioscience and Human Technology

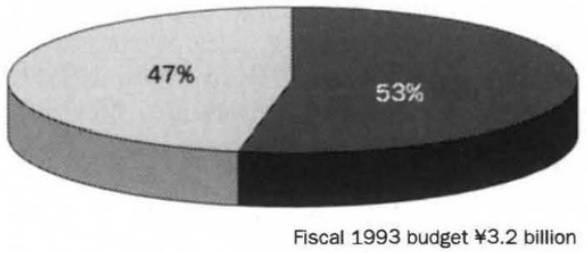

equipment with money from the supplementary budget introduced by the government last October to fight Japan's recession. Starting this autumn, the institute will also be host to researchers from companies participating in the atom technology project.

David Swinbanks

\section{French voters shun 'greens'}

Paris. The major surprise of last Sunday's first round of the French parliamentary elections was the unexpectedly poor showing of the greens, who won only 7.8 per cent of the vote. Last year, the Génération Ecologie/ Verts alliance took 14.7 per cent in regional elections and were expected to win dozens of seats in the 577-seat National Assembly. Although their tally is larger than the 0.4 per cent that they received in the last parliamentary election five years ago, only three ecologist candidates have gone through to the second and decisive round of voting this Sunday, and only one may win a seat.

The fault appears to lie with an ambiguous response to an offer by leading Socialist Michel Rocard to help form a new wider centre-left party, which diminished voter confidence, as well as to a lacklustre campaign and a low turnout, barely two-thirds of the electorate.

Declan Butler 